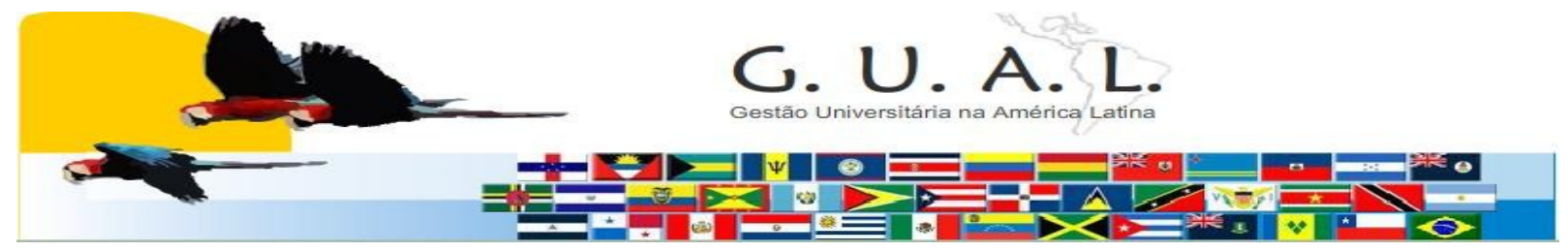

ISSN 1983-4535

\title{
INDICADORES DE RESPONSABILIDADE SOCIAL: UMA PROPOSTA PARA AS INSTITUIÇÕES DE ENSINO SUPERIOR
}

\author{
Vanderléia Martins Lohn, Mestre \\ Universidade do Vale do Itajai - UNIVALI \\ vandalohn@univali.br
}

\begin{abstract}
RESUMO
Este artigo tem por objetivo apresentar uma proposta de indicadores de Responsabilidade Social para Instituições de Ensino Superior - IES, aplicáveis às universidades. O estudo caracterizou-se por um estudo de caso, caráter exploratório, na medida em que busca, através da revisão bibliográfica e estudo do método Delphi, o levantamento de indicadores de Responsabilidade Social. Em seguida, com base na pesquisa de dados primários e secundários, foram gerados instrumentos e levantamentos de dados, definidos como relatórios de geração de idéias, que foram analisados e gerados novos relatórios com base nos indicadores Ethos de Responsabilidade Social. Feito isso, com a participação do moderador da equipe e técnicos, os indicadores foram selecionados, no intuito de contribuir para a disseminação da prática da Responsabilidade Social sustentável na IES. Identificaram-se os indicadores que mais contribuem para implantação da Responsabilidade Social na IES, bem como a viabilidade do negócio da IES.
\end{abstract}

Palavras-chave: Responsabilidade social. Instituição de Ensino Superior. Indicadores. 


\section{INTRODUÇÃO}

O processo de conhecimento está no âmago do processo de desenvolvimento das Instituições de Ensino Superior- IES. A educação superior é, portanto, uma Responsabilidade Social de primeira ordem e pode ser fortalecida significativamente entre o Estado, as Instituições de Ensino Superior e a sociedade, provido de uma reflexão sobre os problemas sociais que refletem a sociedade.

O caminho para a chamada Responsabilidade Social inicia-se com o delineamento estratégico das organizações, com base no estudo da missão da organização e dos aspectos inerentes dos seus atores sociais - stakeholders. Deve-se estabelecer a compreensão do funcionamento da organização em relação ao contexto ambiental, social e econômico no qual está inserida (TACHIZAWA, 2002). Entretanto, a Responsabilidade Social é uma forma de conduzir os negócios das organizações de tal maneira que a torna parceira e co-responsável pelo desenvolvimento social.

A educação superior tem dado ampla prova de sua viabilidade e habilidade para introduzir mudanças e progressos na sociedade, mas ainda para atender às necessidades sociais e promover a solidariedade e a igualdade, deve exercer o rigor da sua Responsabilidade Social, no promover, gerar e difundir conhecimentos, principalmente na parte que tange sua atividade à comunidade.

Este artigo centra sua atenção na Responsabilidade Social para Instituições de Ensino Superior. O artigo tem por objetivo desenvolver uma proposta de indicadores de Responsabilidade Social para Instituições do Ensino Superior - IES, aplicáveis nas universidades, com objetivo de avaliar o grau de sustentabilidade e impacto em termos sociais, econômicos e ambientais. Este levantamento pretende contribuir com a disseminação da prática da Responsabilidade Social sustentável, identificando os interesses de todos aqueles que diretamente ou indiretamente podem impactar ou ser impactados por suas ações, ou seja, os stakeholders que estão em torno da IES, considerando principalmente a comunidade e as gerações futuras.

O papel do pesquisador nesse estudo foi de moderador e animador das reflexões da Responsabilidade Social na IES, utilizando o Método Delphi como ferramenta de pesquisa, geração de idéias sobre os indicadores Ethos, centrando-se na Declaração Mundial sobre Educação Superior da UNESCO. A realização do estudo ocorre mediante sucessivos 
questionamentos entre um grupo de especialistas da IES cujas respostas são analisadas e discutidas entre este grupo com respeito à obtenção ou não do consenso dos indicadores Ethos de Responsabilidade Social para IES em estudo.

O Método Delphi tem por objetivo a geração de idéias entre um grupo de especialistas sobre um determinado questionamento, recomendada para estudos que dispõe de dados não mensuráveis a respeito de um problema que se investiga ou em pesquisas sobre temas recentes (WRIGHT e GIOVINAZZO, 2001). Face a isto, surge o problema a ser pesquisado: indicadores de Responsabilidade Social apropriados às Instituições de Ensino superior, especialmente Universidades.

Por fim, apresentar-se-ão a proposta de indicadores de Responsabilidade Social a serem implantados nas Instituições de Ensino Superior - universidades, caracterizando a missão e função da educação superior - "a missão de contribuir para o desenvolvimento sustentável e o melhoramento da sociedade como um todo, que devem ser preservados, reforçados e expandidos" situados na (Declaração Mundial sobre Educação Superior, 1999).

\section{CONTEXTUALIZANDO INSTITUIÇÕES DE ENSINO SUPERIOR - IES}

O sistema de ensino superior brasileiro passou e ainda vem passando por expressivas mudanças em sua morfologia. A década de 90 correspondeu por impactos expressivos na educação, como a mudança na economia brasileira, resultante do processo de globalização e a incorporação de um público diferenciado, como a entrada de alunos já integrados no mercado de trabalho e também o aumento de mulheres no mercado de trabalho, conseqüente entrada nas Universidades.

$\mathrm{Na}$ década de 30, quando o Brasil começou a formar suas primeiras universidades, modelos foram copiados da Europa, como o modelo Francês, um modelo de universidade organizada de forma centralizada do ponto de vista administrativo, mas fragmentada, do ponto de vista da integração de suas faculdades profissionalizantes. Um modelo profissionalizante que mantém sua influência no caso brasileiro até os dias de hoje, sendo que a partir de 1931 passa a fazer parte da universidade, então instalada, havendo a incorporação não só do modelo profissionalizante, mas a manutenção da cátedra, instituída no período medieval e mantida no modelo napoleônico (JANOTI, 1992).

A instituição universitária brasileira foi uma criação com base em modelos, tendo importante papel unificador da cultura medieval e que, posteriormente, ao longo da sua 
construção, redefinida em suas atribuições e em seu escopo, como ensino - pesquisa extensão, levando em conta as recomendações relativas à educação superior das principais comissões e conferências mundiais, como a UNESCO.

Chauí (2001) menciona que a universidade é uma organização social que presta um serviço ao Estado e celebra com ele um contrato de gestão. Assim, ao descrever a educação no setor serviço, deixa de considerá-la um direito dos cidadãos e passa a identificá-lo como qualquer outro serviço público, sendo que este pode ser privatizado - universidades particulares ou terceirizados.

Em relação a tal aspecto, pode-se dizer que a educação se enquadra nos "serviços de massa", com grau de intensidade de mão-de-obra em alto e com grau de interação e personalização em baixo no entender de Fitzsimmons e Fitzsimmons (2000). Ainda na visão do autor, quanto mais padronizado for o serviço menos personalizado ele é, isto significa que os mais personalizados conduzem a empresa num alto grau de envolvimento.

As Instituições de Ensino Superior são entidades que prestam serviços à sociedade. Devido à sua natureza intangível de produto - serviços têm dificuldades em estabelecer um consenso sobre qualidade. Constroem gerações de profissionais e cidadãos, mas também se encontram resistências às mudanças e transformações do mercado e da sociedade (MENDONÇA, 2002).

Em outro contexto, o artigo 26 da Declaração Universal dos Direitos Humanos, descreve que "toda pessoa tem o direito à educação "e que" a educação superior deverá ser igualmente acessível a todos com base no respectivo mérito", endossado dos princípios básicos da Convenção contra Discriminação em Educação. A educação é um dos pilares fundamentais dos direitos humanos, da democracia e do desenvolvimento sustentável, devendo ser acessível a todos (Declaração Mundial sobre Educação Superior, 1999).

Diante disso, a Declaração Mundial sobre Educação Superior (1999) descreve funções que devem ser implantadas pelas Instituições de Ensino Superior, como artigo principal: a missão de educar, formar e realizar pesquisas, como uma das premissas: "Promover, gerar e difundir conhecimentos por meio da pesquisa e, como parte de sua atividade de extensão à comunidade, oferecer assessorias relevantes para ajudar as sociedades em seu desenvolvimento cultural, social e econômico, promovendo e desenvolvendo a pesquisa científica e tecnológica, assim como os estudos acadêmicos nas ciências sociais e humanas, e a atividade criativa nas artes".

Rev. GUAL., Florianópolis, v.4, n. 1, p.110-128, jan/abr. 2011 
Neste mesmo sentido, Frederico Mayor, Diretor Geral da UNESCO em 1997 descreve que a "educação é a chave do desenvolvimento sustentável, auto-suficiente - uma educação fornecida a todos os membros da sociedade segundo modalidades novas e com a ajuda de tecnologias novas, de tal maneira que cada um se beneficie de chances reais de se instruir ao longo de sua vida. Devemos estar preparados, em todos os países, para remodelar o ensino, de forma a promover atitudes e comportamentos que sejam portadores de uma cultura da sustentabilidade".

No Brasil, cada vez mais é discutido o papel das Instituições de Ensino Superior como agentes sociais no processo de desenvolvimento local e sustentável, destacando-se a sociedade, o ambiente e a economia, que são integrados e se reforçam mutuamente. Sua função também deve ser de refletir sobre os diversos aspectos atinentes à questão da Responsabilidade Social como desenvolver recursos potenciadores de transformação e desenvolvimento local.

\subsection{Responsabilidade Social e Desenvolvimento Sustentável}

O caminho para a chamada Responsabilidade Social inicia-se com o delineamento estratégico das organizações, com base no estudo da missão da organização e dos aspectos inerentes do mercado, concorrentes, fornecedores, cliente interno, comunidade e outros atores sociais - stakeholders. Deve-se estabelecer a compreensão do funcionamento de uma organização em relação ao contexto ambiental no qual está inserida (TACHIZAWA, 2002).

Corroborando com o pensamento de Pontes (2007), o conceito de Responsabilidade Social, vai além dos compromissos compulsórios da empresa, deve expressar a inserção de valores, condutas e procedimentos, que induzem à melhoria de vida dos funcionários e seus familiares e ainda o desenvolvimento sustentável da comunidade no qual está inserido, a fim de pensar na sustentabilidade das gerações futuras a médio e longo prazo.

Essa conceituação incorpora o pensamento de IES descrito na Declaração Mundial sobre Educação Superior e assevera que a educação é a chave para o desenvolvimento sustentável. A definição de Pontes também salienta o valor diante os valores, condutas e procedimentos, vinculando atributos de sustentabilidade das gerações futuras e aos objetivos pretendidos.

A Responsabilidade Social é uma forma de conduzir os negócios das organizações de tal maneira que a torna parceira e co-responsável pelo desenvolvimento social. A organização 
socialmente responsável é aquela que consegue ouvir os interesses das diferentes partes e incorporá-lo no planejamento de suas atividades, buscando atender a todos e não apenas aos acionistas e proprietários.

Ainda, no que tange a Responsabilidade Social, importante destacar o conceito que o Instituto Ethos introduz nas suas atividades. Segundo Arantes et al (apud INSTITUTO ETHOS, 2005, p.126): Responsabilidade Social é uma nova forma de fazer negócios onde a empresa administra suas operações de forma sustentável no âmbito econômico, social e ambiental, reconhecendo os interesses dos distintos públicos com os quais se relaciona, com os seus stakeholders, considerando o meio ambiente e as gerações futuras.

No entanto, a Responsabilidade Social vai além da postura ética da organização, do assistencialismo e ajuda a comunidade. Significa um trabalho de mudança de atitude e comportamento, tendo por conseqüência a consolidação de uma sociedade economicamente e socialmente mais justa. Consolidação esta que pode ser estabelecida por meio de projetos sociais, como uma prática de comprometimento ao meio no qual está inserido (BITTENCOURT; CARRIERI, 2005).

Assim tal estudo, ingressa a chamada parceria - formação de alianças intersetoriais com vistas a canalizar uma maior efetividade para a implantação dos indicadores de Responsabilidade Social nas IES, sendo o meio para alcançar as finalidades desejadas entre os três setores (governo, empresas e representações da sociedade civil). A chamada parceria, para alcançar o propósito, deve conhecer as condições existentes, possibilidades e dificuldades, determinando assim os meios para superar as dificuldades e potencializar as possibilidades, a fim de atingir o resultado proposto.

No tocante às categorias de alianças intersetoriais, identifica-se que colaboração intersetorial não é fácil, mas a parceria nos fatores emergentes, no contexto político, legal e econômico prolifera a construção de pontes entre as organizações e o compromisso dos três setores com o desenvolvimento sustentável, conduzindo a necessidade de reafirmar a formação de alianças estratégicas com o desenvolvimento sustentável (FISCHER, 2002).

O desenvolvimento sustentável é a busca pelo desenvolvimento socioeconômico e ambiental de forma a entender e atender às necessidades das gerações atuais sem comprometer os direitos das gerações futuras. O desenvolvimento sustentável direciona para um repensar sobre a responsabilidade e impactos de todos os atores de uma organização, ou

Rev. GUAL., Florianópolis, v.4, n. 1, p.110-128, jan/abr. 2011 
seja, o envolvimento do primeiro, segundo e terceiro setores no desenvolvimento que pressupõe as gerações futuras (MONTIBELLER FILHO, 2004).

Em outra perspectiva, desenvolvimento sustentável é um processo de transformação, em que a exploração dos recursos, o destino dos investimentos, os rumos do desenvolvimento tecnológico e a mudança institucional devem considerar as necessidades das futuras gerações.

É imperativo abordar, que não vai haver desenvolvimento sustentável sem a participação das IES e das empresas, pois as empresas controlam uma boa parcela do PIB, influenciando na vida das pessoas e no crescimento econômico. Porém, é importante lembrar que as empresas não são as únicas responsáveis pelo desenvolvimento sustentável, as IES também têm uma significativa parcela de responsabilidade, principalmente no que diz respeito ao desenvolvimento sociocultural e econômico para com a construção do futuro, diante o qual as novas gerações deverão estar preparadas.

Segundo Melo Neto e Froes (1999), o processo de desenvolvimento sustentável requer a formação de alianças intersetoriais, idéias e ações desenvolvidas por diferentes organizações, sejam essas, organizações do Primeiro, Segundo e Terceiro Setor, a fim de beneficiar a sociedade como um todo.

No que se refere à Responsabilidade Social nas IES, tais padrões são importantes no que diz respeito aos ativos tangíveis e intangíveis na mensuração dos projetos e ações, embora os estudos e comprovações sejam, em sua maioria, empíricos. Assim, os indicadores sociais deixaram de figurar apenas os diagnósticos e relatórios governamentais ganhando modelos que avaliam e divulgam informações sociais, econômicas e ambientais, perfazendo o tripé do desenvolvimento sustentável.

No tocante, para a pesquisa em estudo, os indicadores de Responsabilidade Social Ethos são vistos como um elo entre os modelos explicativos da teoria e a evidencia empírica dos estudos sociais em observação. Em um olhar mais pragmático, pode-se dizer que o indicador de Responsabilidade Social é um instrumento operacional para monitorar a realidade social, para fins de reavaliação e intervenção na política de gestão da organização em estudo.

Os indicadores Ethos de Responsabilidade Social Empresarial podem ser descritos como uma ferramenta de avaliação e gestão das práticas de Responsabilidade Social no posicionamento estratégico da organização. Estes indicadores possibilitam comparar o 
desempenho da empresa com as demais organizações do seu segmento, analisando os pontos fortes de gestão e as oportunidades de melhoria dentro dos temas de avaliação.

Criado em 2000 pelo Instituto Ethos, os indicadores Ethos são atualizados anualmente e podem ser aplicados por qualquer empresa, distribuído em sete dimensões de avaliação. $\mathrm{O}$ autodiagnóstico da Responsabilidade Social nas empresas abrange dilemas e peculiaridades de cada setor, sendo que existem versões de Indicadores Ethos para setores específicos, como: mercado (Financeiros, Mineração; Papel e Celulose; Construção Civil; Transporte de Passageiros Terrestres; Petróleo e Gás; Panificação; Restaurante e Bar; Varejo), não existindo ainda indicadores específicos para IES.

Abaixo segue o quadro que ilustra as dimensões e indicadores Ethos empresariais que serão utilizados como base para a proposta de indicadores de Responsabilidade Social para as IES.

\section{Quadro 1}

\section{Indicadores Ethos}

\begin{tabular}{|c|l|}
\hline Dimensões Ethos & \multicolumn{1}{c|}{ Indicadores Ethos } \\
\hline \multirow{4}{*}{$\begin{array}{c}\text { Valores, Transparência e } \\
\text { Governança }\end{array}$} & Compromissos Éticos \\
& Enraizamento na Cultura Organizacional \\
& Governança Corporativa \\
& Relações com a Concorrência \\
& Diálogo com Partes Interessadas (Stakeholders) \\
& Balanço Social \\
\hline \multirow{3}{*}{ Público Interno } & Relações com Sindicatos \\
& Relações com Trabalhadores Terceirizados \\
& Gestão Participativa \\
& Compromisso com o futuro das crianças \\
& Compromisso com o desenvolvimento infantil \\
& Valorização da diversidade \\
& Compromisso com a Equidade Racial \\
& Compromisso com a Equidade de Gênero \\
& Política de remuneração, benefícios e carreira \\
\hline \multirow{2}{*}{ Público Interno } & Cuidado com saúde, segurança e condições de trabalho \\
& Compromisso com o desenvolvimento profissional e a \\
& empregabilidade \\
& Comportamento frente a demissões \\
& Preparação para aposentadoria \\
\hline Meio Ambiente & Compromisso com a melhoria da qualidade ambiental \\
& Educação e conscientização ambiental \\
& Gerenciamento do impacto no meio ambiente e do ciclo de \\
& vida de produtos \\
& Minimização de entradas e saídas de materiais \\
\hline & \\
\hline
\end{tabular}

Rev. GUAL., Florianópolis, v.4, n. 1, p.110-128, jan/abr. 2011 


\begin{tabular}{|c|l|}
\hline \multirow{3}{*}{ Fornecedores } & $\begin{array}{l}\text { Critérios de seleção e avaliação de fornecedores } \\
\text { Trabalho infantil na cadeia produtiva }\end{array}$ \\
& Trabalho forçado (ou análogo ao escravo) na cadeia \\
& produtiva \\
& Apoio ao desenvolvimento de fornecedores \\
\hline \multirow{3}{*}{ Consumidores e Clientes } & Política de comunicação comercial \\
& Excelência de atendimento \\
& Conhecimento e gerenciamento dos danos potenciais dos \\
& produtos e serviços \\
\hline \multirow{3}{*}{ Comunidade } & Financiamento da ação social \\
& Envolvimento com a ação social \\
& Gerenciamento do impacto da empresa na comunidade de \\
& entorno \\
& Relações com organizações locais \\
\hline \multirow{3}{*}{ Governo e Sociedade } & Contribuições para campanhas políticas \\
& Construção da cidadania pelas empresas \\
& Práticas anticorrupção e antipropina \\
& Liderança e influencia social \\
& Participção em projetos sociais governamentais \\
\hline
\end{tabular}

Fonte: Instituto ETHOS (2006)

Os indicadores Ethos são aplicados por meio de questionários de fácil preenchimento e entendimento pelo os atores participantes, sendo também um importante momento de participação e diálogo interno que quando bem aproveitado, pode ser uma grande oportunidade de homogeneização dos conceitos de Responsabilidade Social e exercício da gestão participativa.

Segundo Melo e Neto e Froes (2001), para a empresa chegar Gestão de Responsabilidade Social (G.R. S) ou Gestão Social Cidadã, a organização deverá passar por dois estágios, sendo a primeira gestão de Responsabilidade Social interna e o segundo gestão de Responsabilidade Social externa.

Assim, com relação à Responsabilidade Social interna e externa, os indicadores Ethos servem como instrumentos de avaliação e gestão, proporcionados uma escala de medição/valor para avaliar o grau de Responsabilidade Social da organização.

$\mathrm{O}$ artigo em pesquisa analisa os indicadores de Responsabilidade Social Ethos no âmbito das IES, sob a moderação da acadêmica e orientação do grupo de especialistas da IES em estudo. A análise principal desse estudo foi o estudo dos indicadores Ethos de Responsabilidade Social Ethos na IES, utilizando o método de pesquisa Delphi, como 
ferramenta de reflexão e geração de idéias, geração de indicadores de Responsabilidade Social apropriados à IES.

\section{MÉTODO DA PESQUISA}

Para a formulação da proposta de indicadores de Responsabilidade Social para IES é necessário o delineamento estratégico da instituição, com base na missão - função, aspectos inerentes do negócio, órgãos normatizadores e processos sistêmicos.

Um dos aspectos fundamentais para o sucesso da pesquisa foi o estudo do método delphi, que caracteriza-se pela existência de "feedback controlado", ou seja, a comunicação regular entre os participantes do grupo em estudo. Durante as rodadas de discussões, os integrantes do grupo recebem as informações e comentários, podendo mudar ou repensar suas opiniões com argumentos mais apropriados. Os resultados gerados são tabulados e apresentados ao grupo, que elabora uma lista dos fatores mais críticos, no caso em estudo, que, por sua vez são novamente analisadas e apresentadas à equipe (WRIGHT E GIOVINAZTO, 2000).

A pesquisa aplicada neste trabalho tem caráter exploratório descritivo. Na pesquisa exploratória, segundo Silva e Shappo (2002) aprofunda-se conceitos preliminares, muitas vezes inéditos e interessantes, sobre uma determinada temática, de uma forma mais subjetiva e interpretativa, com vistas por tornar essa temática mais explícita. Do ponto de vista da abordagem, o presente estudo tem caráter quanti - quali, que Oliveira (2000) define como método qualitativo mensura o objeto, o método quantitativo mensura suas categorias e atributos tais como: qualidade, relação, ação, paixão, dor, amor, hábitos, atitudes e preferências entre outras variáveis. Com essa técnica busca-se auxiliar o grupo de estudo na captura de conhecimento da IES, análise das informações coletados junto a IES e, por conseguinte, na elaboração da lista de indicadores mais apropriados a IES, por meio da geração de idéias.

\section{DESCRIÇÃO DA PESQUISA}

O objetivo dessa pesquisa era de estabelecer uma proposta de indicadores de Responsabilidade Social para IES, utilizando como estudo os Indicadores Ethos, no que se refere a proposta de modelo. O estudo contemplou a revisão do conhecimento existente na

Rev. GUAL., Florianópolis, v.4, n. 1, p.110-128, jan/abr. 2011 
literatura e estudo das respostas da pesquisa exploratória sobre indicadores Ethos de Responsabilidade Social, o que permitiu a formulação de indicadores apropriados á IES.

Após aplicação do questionário Ethos, o grupo se reuniu para analisar os resultados e opinar sobre possíveis idéias e soluções sobre o objetivo de pesquisa. O questionário aplicado foi tabulado e novamente apresentado ao grupo, que elaborou nova lista de análises e a conclusão do estudo, que por sua vez, foram novamente tabuladas e apresentadas à equipe. As analises foram auxiliadas por critérios como: ordem das perguntas do questionário; importância do indicador para a IES, necessidade e aplicabilidade da questão à organização em estudo.

O questionário, modelo ETHOS aplicado na organização em estudo objetivou identificar as práticas da Responsabilidade Social que a IES desenvolve, como também, mensurar o uso de práticas formais e informais e sua freqüência de uso. Outros pontos de análise ocorreram por conta das razões: utilizar a prática da Responsabilidade Social; os resultados que podem proceder pela aplicabilidade dos indicadores Ethos para a IES; as dimensões e indicadores Ethos são apropriados à IES em estudo; saber se a organização está investindo em Responsabilidade Social.

Cada um desses temas divide-se em várias questões com assertivas em que as respostas podem variar entre Sim e Não e entre Graus de Importância. O modelo de questionário Ethos foi adaptado para à IES em estudo.

Por fim, a equipe elaborou uma lista final de indicadores que podem ser apropriados a IES, apresentado na figura 1.

Os indicadores identificados serão utilizados como base para a proposta de indicadores de Responsabilidade Social para IES, bem como o estudo da cultura organizacional da IES, conforme ilustrado na figura 3, indicada a seguir.

\section{Quadro 2}

\section{Proposta de indicadores de Responsabilidade Social para Instituições de Ensino Superior baseados nos indicadores Ethos.}

\begin{tabular}{|c|ll|}
\hline Dimensões & \multicolumn{1}{c|}{ Indicadores Setoriais - IES } \\
\hline & - & Enraizamento da Declaração Mundial sobre Educação Superior no \\
Valores, & & Século XXI: Visão e Ação (UNESCO) \\
Transparência & - & Compromissos com o ensino \\
e Governança & - & Compromissos com a pesquisa \\
& - & Compromissos com a extensão universitária \\
\hline
\end{tabular}

Rev. GUAL., Florianópolis, v.4, n. 1, p.110-128, jan/abr. 2011 


\begin{tabular}{|c|c|}
\hline & $\begin{array}{lll}\text { - } & \text { Balanço social disponível para seus parceiros } & \\
\text { - } & \text { Responsabilidade Social no posicionamento estratégico da } \\
& \text { Universidade } & \\
\text { - } & \text { Governança corporativa } \\
\text { - } & \text { Dialogo com os seus stakeholders } \\
\text { - } & \text { Compromissos com a educação local } \\
\text { - } & \text { Compromissos com as políticas públicas locais } \\
\text { - } & \text { Valorização do código de ética ou similar }\end{array}$ \\
\hline Público Interno & $\begin{array}{ll}\text { - } & \text { Relações com os sindicatos e representantes de classe } \\
\text { - } & \text { Condições e qualidade de trabalho } \\
\text { - } & \text { Compromisso com os filhos dos funcionários } \\
\text { - } & \text { Educação ambiental com os funcionários } \\
\text { - } & \text { Valorização na participação de cursos } \\
\text { - } & \text { Valorização do funcionário nos projetos sociais da IES } \\
\text { - } & \text { Compromisso com a erradicação do trabalho infantil } \\
\text { - } & \text { Compromisso com a erradicação do trabalho escravo } \\
\text { - } & \text { Compromisso com a equidade racial } \\
\text { - } & \text { Compromisso com a equidade de gênero } \\
\text { - } & \text { Política de remuneração, benefícios e carreira } \\
\text { - } & \text { Preparação para aposentadoria } \\
\text { - } & \text { Comportamento ético frente às demissões }\end{array}$ \\
\hline Meio Ambiente & $\begin{array}{ll}\text { - } & \text { Compromisso com tecnologias mais limpas } \\
\text { - } & \text { Compromisso com reciclagem e reutilização junto ao corpo discente da } \\
& \text { IES } \\
\text { - } & \text { Compromisso com reciclagem e reutilização junto ao corpo docente da } \\
& \text { IES } \\
\text { - } & \text { Minimização do consumo de energia elétrica } \\
\text { - } & \text { Compromisso com a comunidade sobre os resíduos sólidos domésticos } \\
\text { - } & \text { Minimização do consumo de água } \\
\text { - } & \text { Minimização no uso de produtos com impacto ambiental } \\
\text { - } & \text { Educação e conscientização ambiental junto aos seus stakeholders } \\
\text { - } & \text { Política de gestão ambiental nos cursos de graduação } \\
\text { - } & \text { Compromisso com o combate ao desmatamento florestal } \\
\text { - } & \text { Compromisso com o reflorestamento }\end{array}$ \\
\hline Fornecedores & $\begin{array}{ll}\text { - } & \text { Compromisso de Responsabilidade Social junto aos seus fornecedores } \\
\text { - } & \text { Critérios de seleção e avaliação de fornecedores } \\
\text { - } & \text { Trabalho infantil na cadeia produtiva } \\
\text { - } & \text { Trabalho forçado (mão de obra escrava / barata junto) na cadeia } \\
\text { produtiva } & \\
\text { - } & \text { Gerenciamento de informações dos fornecedores }\end{array}$ \\
\hline
\end{tabular}




\begin{tabular}{|c|c|}
\hline $\begin{array}{l}\text { Consumidores } \\
\text { e Clientes }\end{array}$ & $\begin{array}{ll}\text { - } & \text { Política de educação ambiental com seus clientes } \\
\text { - } & \text { Política do consumo consciente com os seus clientes - alunos } \\
\text { - } & \text { Educação e conscientização sobre a Responsabilidade Social } \\
\text { - } & \text { Compromisso com os direitos do consumidor } \\
\text { - } & \text { Compromisso com atendimento de excelência } \\
\text { - } & \text { Ética e transparência na política de preços } \\
\text { - } & \text { Compromisso com o pós-venda do cliente } \\
\text { - } & \text { Política de comunicação comercial junto aos acadêmicos e seus } \\
& \text { familiares } \\
\text { - } & \text { Conhecimento e gerenciamento dos danos potenciais dos serviços }\end{array}$ \\
\hline Comunidade & $\begin{array}{ll}\text { - } & \text { Compromisso com a ação social comunitária } \\
\text { - } & \text { Financiamento dos projetos de ação social local } \\
\text { - } & \text { Apoio na infra-estrutura local } \\
\text { - } & \text { Promociamento do impacto da empresa comunidade de entorno } \\
\text { - } & \text { Fortalecimento da empregabilidade para a comunidade local } \\
\text { - } & \text { Participação da comunidade no desenvolvimento e implantação dos } \\
& \text { projetos de extensão universitária } \\
\text { - } & \text { Compromisso e respeito com a cultura regional e local da comunidade } \\
\text { - } & \text { Política de projetos sociais junto à comunidade local } \\
\text { - } & \text { Relações com organizações locais }\end{array}$ \\
\hline $\begin{array}{l}\text { Governo e } \\
\text { Sociedade }\end{array}$ & $\begin{array}{ll}\text { - } & \text { Compromisso de ética e transparência aos órgãos fiscalizadores } \\
\text { - } & \text { Participação em projetos sociais governamentais } \\
\text { - } & \text { Formação de alianças intersetoriais nos projetos sociais } \\
\text { - } & \text { Promoção de planejamento e gestão social local } \\
\text { - } & \text { Contribuições para campanhas políticas } \\
\text { - } & \text { Praticas de anticorrupção e antiproprina }\end{array}$ \\
\hline
\end{tabular}

Fonte: Dados primários (2008)

O questionário modelo Ethos para realização do estudo sobre Responsabilidade Social foi o principal produto decorrente do método exploratório descritivo nessa pesquisa. Neste estudo o método delphi também contribuiu na sistemática de gerar e refinar idéias oriundas de um grupo de especialistas, sobre um determinado problema, neste caso, a identificação dos indicadores de Responsabilidade Social mais apropriado às IES, com base na teoria estudada e os dados coletados no questionário Ethos.

Os resultados obtidos no questionário foram utilizados pelo grupo para formular os indicadores, através da geração de idéias, estudo exploratório descritivo, na construção da proposta de indicadores de Responsabilidade Social para IES. As análises e idéias geradas foram tabuladas e novamente analisadas pelo grupo, que por final elaborou os indicadores de Responsabilidade Social para IES, apresentada na figura 3. 
Para complementar a proposta acima, comenta-se a importância de envolver sindicatos, associações, entidades representativas das IES e também representação de organizações do Primeiro e Segundo Setor, com a finalidade de trabalhar a formação de alianças intersetoriais na Responsabilidade Social. Trata-se de um compromisso que incentive as práticas de Responsabilidade Social nas IES, ao mesmo tempo em que envolve um pensamento de desenvolvimento sustentável, com vistas às futuras gerações, destacando-se a educação, os projetos de extensão e a conscientização gestora sobre os impactos do seu negócio na sociedade, ou seja, os problemas de ordem social, ambiental e econômica que podem ser realizados pelas IES.

Transformar valores culturais e imprimir-lhes feição ecológica implica ações difusas, descentralizadas e de longo prazo, demanda transformações na educação formal e informal, na tecnologia, na filosofia e nas mentalidades, na forma de conceber e utilizar o mundo e os recursos do ambiente, na mitologia e nas tradições espirituais, em direção à perspectiva pósmaterialista. (RIBEIRO, 2000, p.32).

\section{CONCLUSÃO}

É sabido que o Brasil ainda agasalha graves problemas sociais que vem a exigir, cada vez mais, das pessoas e das organizações, a integração e o comprometimento com soluções eficazes na área social, através do envolvimento do maior número possível de parceiros. A ação planejada e organizada, por meio de alianças e parcerias, pode provocar profundas mudanças socioeconômicas e ambientais em questões que envolvem IES - Universidades. Por essa perspectiva, a Responsabilidade Social deve ser inerente à própria natureza da atividade organizacional, incluindo o gerenciamento do impacto social e desenvolvimento local sustentável.

Embora muitas instituições de estudo já desenvolvam ações de Responsabilidade Social e tenham certo impacto positivo na comunidade e seus stakeholders, ainda existe uma necessidade muito grande de esclarecimentos e práticas de Responsabilidade Social efetiva de modo global, ou seja, a necessidade da contribuição social de todos os setores e agentes participantes das IES.

Neste sentido, considerando-se a Responsabilidade Social como uma nova forma de conduzir os negócios de tal maneira que a torna parceria e co-responsável pelo desenvolvimento sustentável (FREY, 2005) e vista as responsabilidades que a sociedade 
atribui às Universidades sobre o seu papel aspectos sociais (Conferencia..., 1999) descreve-se como premissa básica para a implantação dos indicadores de Responsabilidade Social à IES, a formação de alianças intersetoriais.

Tais indicadores objetivam diagnosticar e analisar os possíveis impactos e hipóteses das IES no desenvolvimento sustentável local, considerando os indicadores de Responsabilidade Social às características inerentes da educação superior, mas apropriadamente ao contexto social - econômico e ambiental das universidades. Exercícios de cidadania e de ética por parte das instituições e, conseqüentemente, de seus colaboradores, enquanto agentes de desenvolvimento local nas regiões em que atuam.

A evolução e a interação são os pontos focais do conceito de desenvolvimento sustentável, em que um conjunto coordenado de processos participativos permite progredir de modo contínuo no debate e no reforço de capacidades de planejamento e mobilização de recursos sociais, econômicos e ambientais da sociedade, a curto e longo prazo, cujo alcance é devido às estratégias articuladas, quando possível e, em caso contrário, depende de arbitragem e conciliação (OCDE, 2001 apud CUNHA; CUNHA, 2005 p. 03).

A iniciativa dos indicadores destaca-se pelo envolvimento com seus stakeholders e padrões que possam medir o impacto das IES no desenvolvimento local, o que pode resultar no implantar uma gestão socialmente responsável, disseminando informações sobre o bom manejo social - projetos de extensão e princípios do compromisso com o desenvolvimento sustentável, ou seja, ações equilibradas no âmbito social, econômico e ambiental, com vistas as gerações futuras.

Ainda dentro dos indicadores sugeridos, tem-se uma atenção especial aos projetos de extensão, como um indicador importante para as universidades de maneira mais criteriosa e direcionada à realidade de cada comunidade, e também à participação de pessoas que residem na comunidade local. Sendo este indicador um caminho para o desenvolvimento local, que pode ser realizado de forma planejada e contínua, buscando atender as necessidades da comunidade e contribuindo para a gestão por resultados das IES

Em suma, o referido artigo apresenta uma proposta de indicadores de Responsabilidade Social para as IES baseados nos indicadores Ethos, com vistas a estabelecer aposição ética e o compromisso com a sociedade perante os indicadores propostos.

Os indicadores propostos no artigo propiciaram classificar, por grau de dimensão, critérios de avaliação de ações, por meio de indicadores. Os indicadores que merecem 
destaque entre as dimensões de público interno (compromissos com ensino - pesquisa extensão, compromisso com educação local e valorização do código de ética ou similar); público interno (condições e qualidade de trabalho, educação ambiental com funcionários, política de remuneração, benefícios e carreira e comportamento ético frente às demissões); meio ambiente (minimizar o consumo de água e energia, compromisso com a reciclagem e política de gestão ambiental nas disciplinas de graduação); consumidores e clientes (política de educação ambiental com seus clientes, compromisso com os direitos do consumidor e compromisso com o pós-venda do cliente); comunidade ( financiamento dos projetos de ação social local, apoio na infra-estrutura local, promoção do crescimento sustentável local e participação da comunidade no desenvolvimento e implantação dos projetos de extensão universitária) são resultados de curto e médio prazo, geradores de receita e lucratividade para a IES, bem como os projetos de extensão que devem ser direcionados as necessidades da IES e da comunidade.

Entretanto, os demais indicadores também devem ser analisados no contexto de importância para a IES, considerando-se as necessidades da IES em estudo. Ou seja, no momento do estudo - geração de idéias do grupo especialista foi identificado estes indicadores, no entanto, outros indicadores podem surgir durante o estudo e, devem ser introduzidos na proposta da IES.

Por fim, indentifica-se que há muito espaço para pesquisas futuras sobre Responsabilidade Social nas IES, especificamente nas universidades. Visando explorar os pontos não tratados neste estudo, sugere-se a aplicação dos indicadores aqui propostos numa IES - Universidades, propondo o método delphi como aplicação e não somente como estudo, no intuito de apresentar a equação de cada indicador e os caracteres para mensurar o resultado esperado do indicador em relação ao negócio da IES.

\section{REFERÊNCIAS}

BITTENCOURT, Epaminondas; CARRIERI, Alexandre. Responsabilidade social: ideologia, poder e discurso na lógica empresarial. Revista de Administração, São Paulo, v. 45, p. 1022, 2005.

CONFERENCIA MUNDIAL SOBRE O ENSINO SUPERIOR; UNESCO; CONSELHO DE REITORES UNIVERSIDADES BRASILEIRAS. Tendências da educação superior para o século XXI. 2 ed. Brasilia: Unesco: CRUC, 1999. 726p. 
CUNHA, Sieglinde Kinfj; CUNHA, João C. Competitividade e sustentabilidade de um cluster de turismo: uma proposta de modelo sistêmico de medida do impacto do turismo no desenvolvimento Disponível em: $<$ http://anpad.org.br/periodicos/content/frame_base. php?revista=1>. Acesso em: 25 out. 2007.

FISCHER, Rosa Maria. O desafio da colaboração: práticas de responsabilidade social entre empresas e terceiro setor. São Paulo: Gente, 2002.

FREY, Irineu Afonso. Sistema de gerenciamento da Responsabilidade Social empresarial por meio de indicadores. 2005. Tese (Doutorado em Engenharia de Produção) - Programa de Pós-graduação em Engenharia de Produção, Universidade Federal de Santa Catarina, Florianópolis, 2005.

CHAUÍ, M. Escritos sobre a universidade. São Paulo: UNESP, 2001.

FITZSIMMONS, James A.; FITZSIMMONS, Mona J. Administração de serviços: operações, estratégia e tecnologia de informação. 2. ed. Porto Alegre: Bookman, 2000.

INSTITUTO ETHOS. Indicadores Ethos de responsabilidade social empresarial. Disponível em: <www.uniethos.org.br/docs/conceitos_praticas/indicadores/ autodiagnosticosetorial/>. Acesso em: 26 nov. 2007.

Indicadores Ethos de responsabilidade social empresarial 2005. São Paulo: Instituto Ethos, 2005.

JANOTI, Aldo. Origens da universidade: a singularidade do caso português. 2. ed. São Paulo: Ed. Universidade de São Paulo, 1992.

MENDONÇA, A W. A universidade no Brasil. Revista Brasileira de Educação, n. 14, p. 131-150, maio/ago. 2000.

MELO NETO, Francisco Paulo; FROES, César. Gestão de Responsabilidade Social Corporativa: o caso brasileiro. Rio de Janeiro: Qualitymark, 2001.

MELO NETO, Francisco Paulo de; BRENNAND, Jorgiana Melo. Empresas Socialmente Sustentáveis: o novo desafio da gestão moderna. Rio de Janeiro: Qualitimark, 2004.

MONTIBELLER FILHO, Gilberto. O Mito do desenvolvimento sustentável: meio ambiente e custos sociais no moderno sistema produtor de mercadorias. Florianópolis: Ed. UFSC, 2004. PONTES, Joseane. Proposta para avaliação do impacto das ações praticadas por uma empresa e sua relação com os indicadores de desempenho. 2007. Tese (Doutorado em Engenharia de Pordução) - Programa de Pós-graduação em Engenharia de Produção, Universidade Federal de Santa Catarina, Florianópolis, 2007.

TACHIZAWA, Takesky. Gestão ambiental e responsabilidade social corporativa: estratégias de negócios focadas na realidade brasileira. São Paulo: Atlas, 2002. 
WRIGHT, J. T. C.; GIOVINAZZO, R. A. Delphi: uma ferramenta de apoio ao planejamento prospectivo. Cadernos de Pesquisa em Administração, São Paulo, v. 1, n. 12, p. 54-65, 2000. 


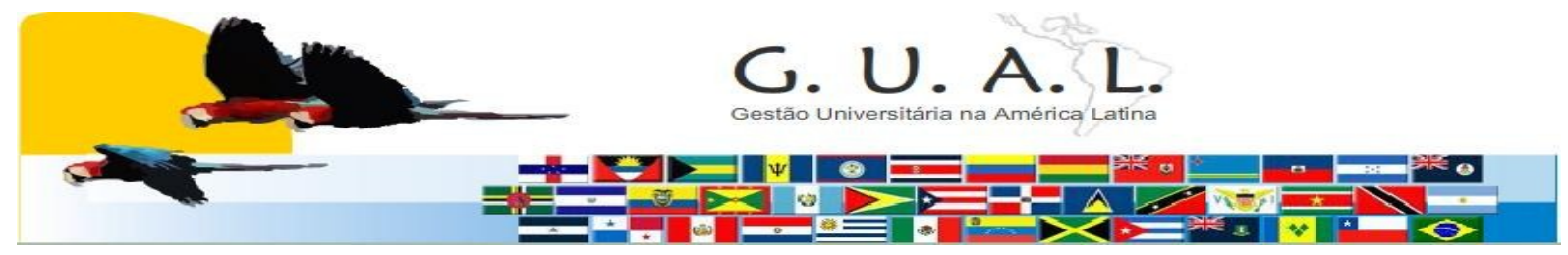

ISSN 1983-4535

\title{
Indicators of social responsibility: a proposal for the Higher Education Institutions
}

\author{
Vanderléia Martins Lohn, Master \\ Universidade do Vale do Itajai - UNIVALI \\ vandalohn@univali.br
}

\begin{abstract}
This paper intends to present the a proposal for indicators of Social Responsibility for Higher Education Institutions - HEI applying to universities. The study was characterized by a case study, exploratory, in that it seeks, through literature review and study of the Delphi method, the survey on Social Responsibility. Then, based on a survey of primary and secondary data were generated instruments and survey data, defined as reports of generating ideas, which were analyzed and generated new reports based on Ethos indicators for Social Responsibility. That done, with the participation of the moderator team and speciality, indicators were selected in order to contribute to the spread of the practice of Social Responsibility in Sustainable IES. Identified the indicators that contribute to implementation of Social Responsibility in HEIs and the business viability of HEI.
\end{abstract}

Keywords: Responsibility. Institution of higher education. Indicators. 